\title{
Moisture Stress Conditioning Effects on Salvia splendens 'Bonfire'
}

\author{
D. Joseph Eakes ${ }^{1}$, Robert D. Wright ${ }^{2}$, and John R. Seiler ${ }^{3}$ \\ Department of Horticulture, Virginia Polytechnic Institute and State University, Blacksburg, \\ VA 24061
}

\begin{abstract}
Additional index words. photosynthesis, transpiration, leaf conductance, mesophyll resistance, water potential, water-use efficiency

Abstract. We determined the influence of moisture stress conditioning (MSC) (exposing plants to four nonlethal drydown cycles) on gas exchange and water loss of Salvia splendens F. Sellow 'Bonfire'. During day 1 following final irrigation, no differences in leaf water potentials $\left(\psi_{L}\right)$ were observed due to MSC. However, MSC plants had lower midday net photosynthesis $(\mathrm{Pn})$, transpiration $(\mathrm{E})$, and leaf conductance $\left(\mathrm{g}_{\mathrm{L}}\right)$ than controls. Stomatal inhibition of photosynthesis (SI) of MSC plants was greater than that of controls. Further, the lack of differences in mesophyll resistance to $\mathrm{CO}_{2}\left(\mathrm{r}_{\mathrm{m}}\right.$ due to $\mathrm{MSC}$ indicate gas exchange differences during day 1 were stomatal in nature. During day 2, MSC plants exhibited greater Pn, E, and $g_{L}$, while SI and $r_{m}$ were greater for controls. MSC plants maintained positive Pn rates and turgor and lower $\psi_{L}$ than control plants during day 2. Higher water-use efficiency estimates were observed for MSC plants than for controls.
\end{abstract}

Bedding plant growers are becoming more aware of the need for improved postproduction performance (Armitage, 1986; Hammer, 1988). Current recommendations for improving postproduction performance include reducing irrigation frequency, fertilization, and greenhouse temperatures during the final few weeks of production (Armitage, 1987; Seeley, 1985). Such hardening-off steps prepare plants for suboptimal conditions often encountered during shipping, in the retail marketplace, and/or during landscape establishment.

Moisture stress is one of the major factors in quality loss following wholesale production (Nelson and Carlson, 1987). Armitage and Kowalski (1983) have demonstrated the positive influence of low-frequeney irrigation regimes on postproduction plant quality of Petunia $\times$ hybrida seedlings. However, plants were not exposed to moisture stress following production.

MSC, the controlled exposure of plants to moisture deficits during production, has been shown to improve physiological processes directly related to moisture stress tolerance of several agronomic (Ackerson and Hebert, 1981; Brown et al., 1976; Gupta and Berkowitz, 1987; Matthews and Boyer, 1984) and woody (Osonubi and Davies, 1981; Seiler, 1985; Seiler and Johnson, 1988) plant species. These physiological acclimations following MSC include the maintenance of greater stomatal conductance and photosynthesis when compared to controls during potentially detrimental internal moisture levels. Armitage et al. (1983) reported that photosynthesis in hybrid geranium declined at a slower rate as soil moisture levels dropped if the plants were previously exposed to a single moisture stress cycle. Despite these reports, more information is needed about the influence of MSC on essential physiological processes required to facilitate the maintenance of postproduction bedding plant quality. Therefore, the objective of this study was to determine the influence of MSC on gas exchange and water loss of salvia.

Received for publication 9 Jan. 1990. Technical guidance and support from Ronald Eakes and Carol Leda are greatly appreciated. The cost of publishing this paper was defrayed in part by the payment of page charges. Under postal regulations, this paper therefore must be hereby marked advertisement solely to indicate this fact.

'Former Graduate Student. Present address: Dept. of Horticulture, Auburn Univ., AL 36849.

${ }^{2}$ Professor.

${ }^{3}$ Assistant Professor, Dept. of Forestry.

\section{Materials and Methods}

Seed of 'Bonfire' salvia were sown on 11 Jan. 1988 and transplanted 14 days later into $500-\mathrm{ml}$ plastic pots containing a 1 peat : 1 perlite $(\mathrm{v} / \mathrm{v})$ medium amended with $1 \mathrm{~kg}$ Micromax (Sierra Chemical Co., Milpitas, Calif.) and $3 \mathrm{~kg}$ dolomitic limestone $/ \mathrm{m}^{3}$. Plants were grown in a glasshouse under long-day conditions [night interruption from 2200 to $0200 \mathrm{HR}$ using incandescent lights providing $\approx 4 \mu \mathrm{mol} \cdot \mathrm{s}^{-1} \cdot \mathrm{m}^{-2}$ photosynthetic photon flux (PPF) at the top of the plant canopies to extend vegetative growth.

Plants were fertilized with $200 \mathrm{mg} \mathrm{N} / \mathrm{liter}$ as $\mathrm{NH}_{4} \mathrm{NO}_{3}, 25 \mathrm{mg}$ $\mathrm{P} /$ liter as phosphoric acid, and $150 \mathrm{mg} \mathrm{K} /$ liter as $\mathrm{KCl}$ in the irrigation water. Forty-nine days after seeding, half of the plants were subjected to MSC by exposing them to four nonlethal drydown cycles and by allowing them to reach visible wilt $\left(\psi_{\mathrm{L}}=\right.$ -1.1 to $-1.4 \mathrm{MPa}$ ) before dehydration. Plant water status was monitored during dry-down cycles by determining $\psi_{\mathrm{L}}$ on a single leaf for three randomly selected MSC plants twice daily using a pressure chamber (Scholander et al., 1965). Control plants were maintained well-watered by applying small amounts of tap water as needed to prevent leaching. Post-dry-down rehydration was accomplished by submersing MSC and control plant containers in the irrigation nutrient solution for $\approx 20 \mathrm{~min}$.

On day 69 after seeding (21 Mar.), plants were irrigated at $0545 \mathrm{HR}$ and placed under supplemental lighting provided with 1000-W high-pressure sodium lamps for gas exchange measurements. The experimental design was a randomized complete block with 10 blocks; one plant per treatment per block (20 plants total). Gas exchange was measured hourly for each plant on the same recently matured leaf during 0900 to $1600 \mathrm{HR}$ on 21 Mar. and 0900 to 1200 HR on 22 Mar. 1988 (days 69 and 70 after seeding, respectively). Pn, E, $\mathrm{g}_{\mathrm{L}}$, gas analyzer leaf chamber $\mathrm{CO}_{2}$ concentration (CA), and leaf internal $\mathrm{CO}_{2}$ concentration (CI) were obtained with a LI-COR (Lincoln, Neb.) 6200 photosynthesis system. Levels of PPF were maintained between 600 and $720 \mu \mathrm{mol} \cdot \mathrm{s}^{-1} \cdot \mathrm{m}^{-2}$. Mean gas analyzer leaf chamber relative humidity, temperature, and $\mathrm{CO}_{2}$ concentra-

\footnotetext{
Abbreviations: $\mathrm{CA}$, leaf chamber $\mathrm{CO}_{2}$ concentration; $\mathrm{CI}$, leaf internal $\mathrm{CO}_{2}$ concentration; E, transpiration; $\mathrm{g}_{\mathrm{L}}$, leaf conductance; MSC, moisture stress conditioning; Pn, net photosynthesis; $\mathrm{r}_{\mathrm{m}}$, mesophyll resistance to $\mathrm{CO}_{2}$; $\mathrm{SI}$, stomatal inhibition of photosynthesis; WUE, water-use efficiency; $\psi_{\mathrm{L}}$, leaf water potential.
} 
tions during measurements were $36 \% \pm 6 \%, 26 \pm 3 \mathrm{C}$, and $361 \pm 26 \mathrm{mg} \cdot$ liter $^{-1}$, respectively. Water-use efficiency (WUE) was calculated by dividing simultaneous Pn measurements by E rates. $r_{m}$ and SI were determined as follows: $r_{m}=C I / P n$ (Osonubi and Davies, 1980), and SI $=[(\mathrm{CA}-\mathrm{CI}) / \mathrm{CA}] \times$ 100 (Jones, 1985).

To prevent significant losses in total leaf area during $\psi_{\mathrm{L}}$ measurements, three blocks were randomly selected for readings at 0630, 1200, and $1630 \mathrm{HR}$ on both days. Water potential was measured on single leaves using a pressure chamber (Scholander et al., 1965). Total leaf area and total shoot dry weight were determined at the end of the experiment. Data were subjected to analysis of variance. Gas exchange and water status data were analyzed within each observation time.

\section{Results}

E (Fig. 1A) and $g_{\mathrm{L}}$ (Fig. 1B) during day 1 following final irrigation were lower for MSC than for control plants, except at $1600 \mathrm{HR}$. Initial E rates for MSC plants on day 2 were similar to those for the end of day 1, but initial $\mathrm{E}$ for control plants on day 2 were $54 \%$ lower than the previous day. Leaf conductance for MSC plants during day 2 was also higher than for controls and declined over time for both treatments.

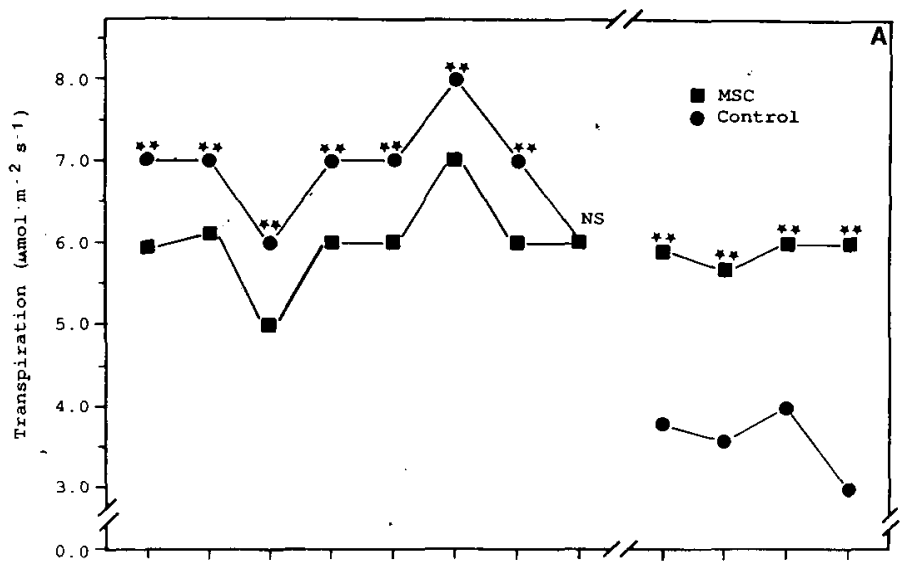

09001000110012001300140015001600 Day 1 (HR)

Day 2 (HR)

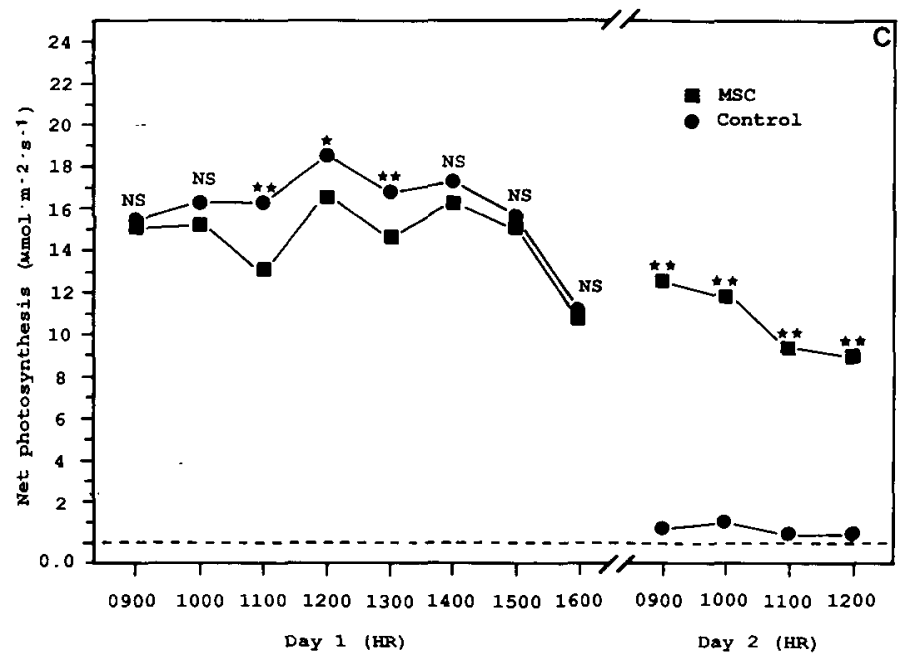

Midday Pn was lower for MSC plants than controls during day 1 (Fig. 1C) but, as with E, was higher than for the control throughout day 2. All MSC plants maintained positive Pn rates throughout day 2, with a final mean rate of $2.5 \mu \mathrm{mol} \cdot \mathrm{s}^{-1} \cdot \mathrm{m}^{-2}$ at $1630 \mathrm{HR}$ (data not shown). SI was greater for MSC plants than for controls throughout day 1 , but during day 2 , it had decreased for control plants and was much lower than for MSC plants (Table 1). There were no differences in $r_{m}$ due to MSC on day 1 , but during day $2, r_{m}$ for control plants had increased dramatically compared to the previous day and was much higher than for MSC plants. WUE was greater for MSC plants than for controls throughout most of day 1 and was dramatically different throughout day 2 (Fig. 1D).

MSC had no affect on $\psi_{L}$ during day 1 (Table 2). However, $\psi_{\mathrm{L}}$ for control plants was lower than for MSC plants during the first observation of day $2(0630 \mathrm{HR})$. Although this was the extent of $\psi_{\mathrm{L}}$ effects, control plants were visibly wilted at 1200 $\mathrm{HR}$, with a mean $\psi_{\mathrm{L}}$ of $-1.28 \mathrm{MPa}$; MSC plants showed no visible turgor loss at $\psi_{\mathrm{L}}=-0.98 \mathrm{MPa}$. MSC plants were still turgid at the end of the experiment $(1630 \mathrm{HR})$, with a mean $\psi_{\mathrm{L}}$ of $-1.30 \mathrm{MPa}$.

MSC reduced shoot dry weight and total leaf area by $42 \%$ and $25 \%$, respectively, compared to controls (Table 3 ).
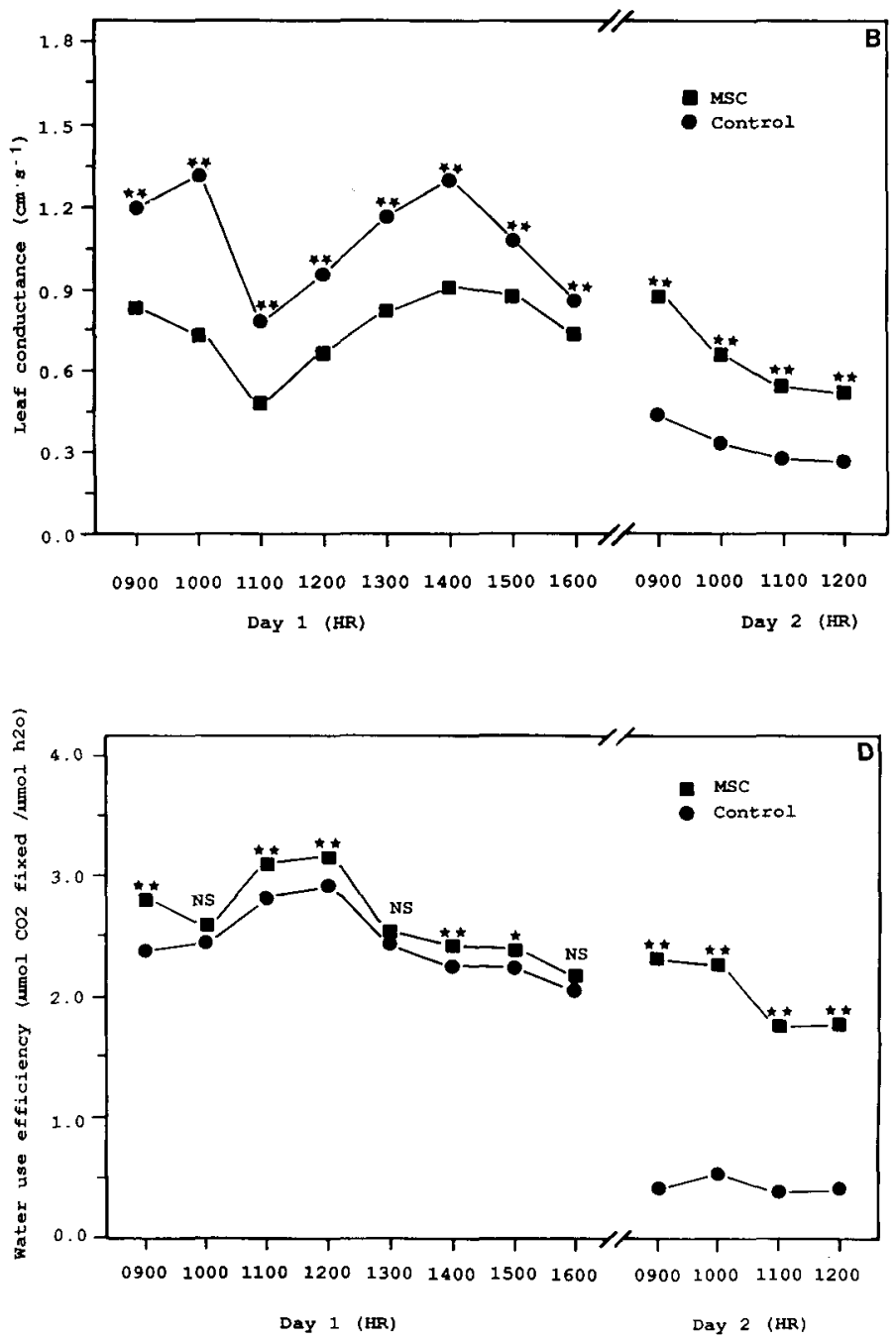

Fig. 1. Transpiration (A), leaf conductance (B), net photosynthesis (C), and water-use efficiency (D) of Salvia splendens 'Bonfire' during the onset of moisture stress as influenced by MSC. Differences between treatment means within an observation time not significant (NS) or significant at $P=0.05\left(^{*}\right)$ or $0.01\left(^{* *}\right)$ by F test. 
Table 1. Mesophyll resistance to $\mathrm{CO}_{2}$ and stomatal inhibition of $\mathrm{Pn}$ of Salvia splendens 'Bonfire' during the onset of moisture stress as influenced by MSC.

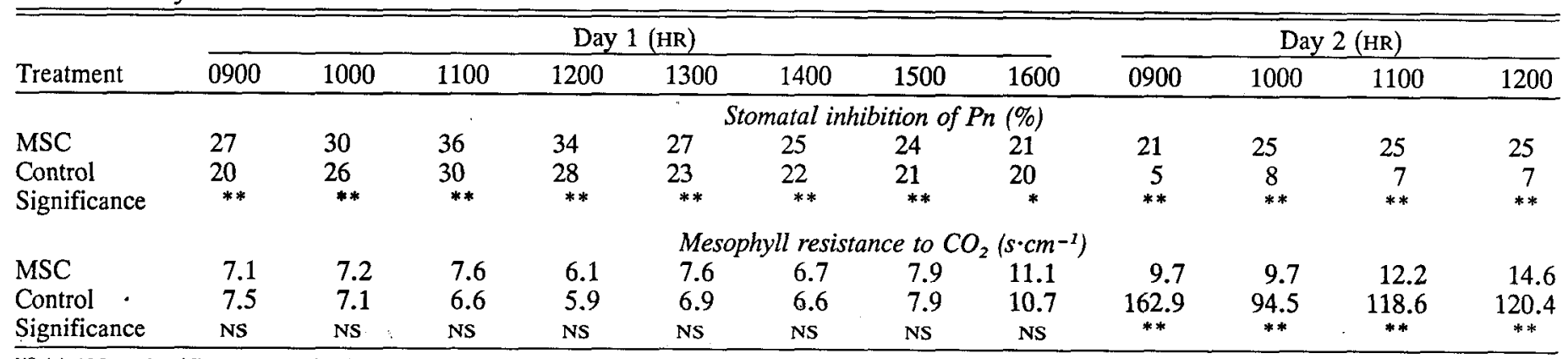

NS,**,*Not significant and significant at $P=0.01$ and 0.05 , respectively, by $\mathrm{F}$ test.

Table 2. Leaf water potential of Salvia splendens 'Bonfire' during the onset of moisture stress as influenced by MSC.

\begin{tabular}{|c|c|c|c|c|c|c|}
\hline \multirow[b]{3}{*}{ Treatment } & \multicolumn{6}{|c|}{ Leaf water potential $(-\mathrm{MPa})^{2}$} \\
\hline & \multicolumn{3}{|c|}{ Day 1 (HR) } & \multicolumn{3}{|c|}{ Day 2 (HR) } \\
\hline & 0630 & 1200 & 1630 & 0630 & 1200 & 1630 \\
\hline MSC & 0.14 & 1.06 & 0.62 & 0.22 & 0.98 & 1.30 \\
\hline Control & 0.22 & 0.77 & 0.59 & 0.64 & $1.28^{y}$ & -- \\
\hline Significance & NS & NS & NS & $*$ & NS & $\cdots$ \\
\hline
\end{tabular}

${ }^{2}$ Means at each time are for three randomly selected plants per treatment.

yAll control plants showing visible wilt.

NS, Not significant and significant at $P=0.05$, respectively, by F test.

Table 3. Shoot dry weight and total leaf area of Salvia splendens 'Bonfire' as influenced by MSC.

\begin{tabular}{lcc}
\hline & $\begin{array}{c}\text { Shoot } \\
\text { dry wt } \\
(\mathrm{g})\end{array}$ & $\begin{array}{c}\text { Total } \\
\text { leaf area } \\
\left(\mathrm{cm}^{2}\right)\end{array}$ \\
\hline Treatment & 4.7 & 941 \\
Control & 8.1 & 1267 \\
Significance & $* *$ & $* *$ \\
\hline
\end{tabular}

**Significant at $P=0.01$ by $\mathrm{F}$ test.

\section{Discussion}

MSC improved tolerance of salvia to moisture stress through reductions in water loss, as indicated by lower E during day 1 compared to control plants. The reductions in $\mathrm{E}$ appear to be due to lower $\mathrm{g}_{\mathrm{L}}$ for MSC plants compared to controls. Experiments with two tree species have also shown similar responses in $\mathrm{E}$ and $\mathrm{g}_{\mathrm{L}}$ (Seiler, 1985; Seiler and Johnson, 1988). Low $\mathrm{g}_{\mathrm{L}}$ values, as seen in this experiment, have been well correlated with reduced stomatal apertures (Burrows and Milthorpe, 1976), which could account for reduced water loss by MSC plants.

Reductions in stomatal aperture during day 1 could also explain reductions in midday $\mathrm{Pn}$ for MSC plants compared to controls. SI rather than non-SI for MSC plants is substantiated by increased SI compared to controls, with no differences in $r_{m}$ due to MSC. Although midday Pn for MSC plants was lower than that for controls, WUE was higher in MSC plants than in controls, indicating that $\mathrm{E}$ was reduced to a greater extent than Pn following MSC. Others, working with tree species, also have reported increased WUE following MSC (Clemens and Jones, 1978; Seiler and Johnson, 1988).

Reductions in transpirational water loss due to less total leaf area and lower E (per unit leaf area) during day 1 for MSC plants delayed the onset of detrimental internal moisture levels and allowed a higher rate of gas exchange during day 2 than in the controls. Initial $\mathrm{E}$ and $\mathrm{g}_{\mathrm{L}}$ values for MSC plants on day 2 were similar to those recorded on day 1 , while being drastically reduced for control plants. Lower mean $\psi_{\mathrm{L}}$ at $0630 \mathrm{HR}$ on day 2 for control plants suggests that control plants were unable to fully rehydrate overnight, reducing stomatal apertures during day 2. The onset of stomatal closure for annual plants has been reported to occur at $\psi_{\mathrm{L}}$ of -0.7 to $-1.6 \mathrm{MPa}$ (Hsiao, 1973). The hypothesis that water was sufficiently limiting for control plants to reduce stomatal opening is supported by reductions in $\mathrm{E}$ and $\mathrm{g}_{\mathrm{L}}$ during day 2. Although Pn for control plants was also lower during day 2, nonstomatal limitations to Pn appear to be greater than stomatal limitations. Mesophyll resistance to $\mathrm{CO}_{2}$ increased more than 10 times and SI dropped by $70 \%$ to $75 \%$ during day 2 compared to day 1 , indicating direct disruption of the photosynthetic mechanism rather than reductions of internal $\mathrm{CO}_{2}$ concentrations due to stomatal closure.

Maintenance of greater Pn rates for MSC plants during day 2 was due not only to reductions in water loss during day 1 , but also to the ability of plants to maintain $\mathrm{Pn}$ at low $\psi_{\mathrm{L}}$. By 1630 HR on day 2, MSC plants maintained a mean Pn rate of $2.5 \mu \mathrm{mol} \cdot \mathrm{s}^{-1} \cdot \mathrm{m}^{-2}$ with a mean $\psi_{\mathrm{L}}$ of $-1.30 \mathrm{MPa}$. By contrast, at $1200 \mathrm{HR}$ on day 2 , control plants had a mean $\psi_{\mathrm{L}}$ of -1.28 $\mathrm{MPa}$ and a mean Pn of $0.4 \mu \mathrm{mol} \cdot \mathrm{s}^{-1} \cdot \mathrm{m}^{-2}$. This photosynthetic acclimation of MSC plants to low $\psi_{\mathrm{L}}$ appears to be due to both stomatal and nonstomatal changes with low $r_{m}$ and greater $g_{\mathrm{l}}$ for MSC plants at similar $\psi_{\mathrm{L}}$ compared to those for control plants. Photosynthetic acclimation to low $\psi_{\mathrm{L}}$ following MSC has also been reported for several agronomic crops (Ackerson and Hebert, 1981; Ashton, 1956; Brown et al., 1976; Gupta and Berkowitz, 1987; Matthews and Boyer, 1984) and woody plant species (Seiler and Johnson, 1988). Despite the lack of agreement attributing these Pn adaptations to stomatal or nonstomatal factors, these authors agree that osmotic adjustment is involved by allowing the plant to maintain turgor during moisture deficits (Brown et al., 1976; Gupta and Berkowitz, 1987; Matthews and Boyer, 1984).

Plant growth was reduced by MSC, a common (Osonubi and Davies, 1978; Seiler, 1985; Seiler and Johnson, 1988), but not universal occurrence (Clemens and Jones, 1978; Osonubi and Davies, 1978). Reduction in plant growth during MSC is probably due to loss of turgor during subsequent dry-down cycles. Turgor loss during moisture stress has been shown to reduce cell division and elongation, as well as essential metabolic processes required for plant growth and development (Hsiao, 1973). Although MSC plants in this study had a mean shoot dry weight that was $\approx 42 \%$ less than that for controls, leaf area was reduced to a lesser degree, giving the MSC plants a shorter 
but fuller appearance when compared to controls. Despite differences in plant size, floral initiation was evident for both MSC and control plants at termination of the experiment on day 71 following seeding, indicating that MSC should not increase the production time required to produce saleable plants.

Results from this work indicate the use of MSC for salvia could prove important to wholesale growers despite reductions in plant size. Moisture stress conditioning of salvia improved moisture stress tolerance through reductions in transpirational water loss and the ability to maintain Pn to lower $\psi_{L}$ than in control plants. Improvements in moisture stress tolerance should allow visual quality to be maintained longer and should reduce plant mortality following wholesale production.

\section{Literature Cited}

Ackerson, R.C. and R.R. Hebert. 1981. Osmoregulation in cotton in response to water stress. Plant Physiol. 67:484-488.

Armitage, A.M. 1986. Growers' most common problems. Greenhouse Grower 4(12):34-36.

Armitage, A.M. 1987. Postproduction care of bedding plants. Greenhouse Grower 5(4):44-45.

Armitage, A.M. and T. Kowalski. 1983. Effect of irrigation frequency during greenhouse production on the postproduction quality of $\mathrm{Pe}$ tunia $\times$ hybrida Vilm. J. Amer. Soc. Hort. Sci. 108(1):118-121.

Armitage, A.M., H.M. Vines, Z.P. Tu, and C.C. Black. 1983. Water relations and net photosynthesis in hybrid geranium. J. Amer. Soc. Hort. Sci. 108(2):310-314.

Ashton, F.M. 1956. Effects of a series of cycles of alternating low and high soil water contents on the rate of apparent photosynthesis in sugar cane. Plant Physiol. 31:266-274.

Brown, K.W., W.R. Jordan, and J.C. Thomas. 1976. Water stress induced alterations of the stomatal response to decreases in leaf water potential. Physiol. Plant. 37:1-5.

Burrows, F.J. and F.L. Milthorpe. 1976. Stomatal conductance in the control of gas exchange, p. 103-152. In: T.T. Kozlowski (ed.). Water deficits and plant growth. Academic, New York.

Clemens, J. and P.G. Jones. 1978. Modification of drought resistance by water stress conditioning in Acacia and Eucalyptus. J. Expt. Bot. 29:895-904.

Gupta, A.S. and G.A. Berkowitz. 1987. Osmotic adjustment, symplast volume, and nonstomatally mediated water stress inhibition of photosynthesis in wheat. Plant Physiol. 85:1040-1047.

Hammer, P.A. 1988. Growing ideas. GrowerTalks 52(10):74.

Hsiao, T.C. 1973. Plant responses to water stress. Annu. Rev. Plant Physiol. 24:519-570.

Jones, H.G. 1985. Partitioning stomatal and non-stomatal limitations to photosynthesis. Plant, Cell \& Env. 8:95-104.

Matthews, M.A. and J.S. Boyer. 1984. Acclimation of photosynthesis to low leaf water potentials. Plant Physiol. 74: 161-166.

Nelson, L. and W. Carlson. 1987. Improve the marketability of bedding plants. Greenhouse Grower 5:84-85.

Osonubi, O. and W.J. Davies. 1978. Solute accumulation in leaves and roots of woody plants subjected to water stress. Oecologia 32:323332 .

Osonubi, O. and W.J. Davies. 1980. The influence of plant water stress on stomatal control of gas exchange at different levels of atmospheric humidity. Oecologia 46:1-6.

Osonubi, O. and W.J. Davies. 1981. Root growth and water relations of oak and birch seedlings. Oecologia 51:343-350.

Scholander, P.F., H.T. Hammel, E.D. Bradstreet, and E.P. Hemmingsen. 1965. Sap pressure in vascular plants. Science 148:339346.

Seeley, J.G. 1985. Finishing bedding plants-Effects of environmental factors, p. 238-241. In: J.W. Mastalerz and E.J. Holcomb (eds.). Bedding plants III. Pennsylvania Flower Growers, University Park, $\mathrm{Pa}$.

Seiler, J.R. 1985. Morphological and physiological changes in black alder induced by water stress. Plant, Cell \& Env. 8:219-222.

Seiler, J.R. and J.D. Johnson. 1988. Physiological and morphological responses of three half-sib families of loblolly pine to water-stress conditioning. For. Sci. 34:487-495. 